\title{
Effects of soil structure interaction on behavior of reinforced concrete structures
}

\author{
S. Kilicer ${ }^{1}$, K. Ozgan ${ }^{* 2}$ and A. Daloglu ${ }^{2}$ \\ ${ }^{1}$ Artvin Çoruh University, Faculty of Engineering, Artvin, Turkey \\ ${ }^{2}$ Karadeniz Technical University, Department of Civil Engineering, Trabzon, Turkey
}

\begin{abstract}
The effects of the subsoil have a very important role on the behavior of the structures. For many years, these effects have been neglected and the superstructure is designed without considering the soil-structure interaction. However, earthquakes in recent years have clearly shown the importance of soil-structure interaction on the design of the structures, and studies on soil-structure interaction have increased especially in the last 50 years. In this study, the effect of soil-structure interaction on behavior of reinforced concrete structures is investigated. The effect of subsoil has been taken into account using Winkler and Vlasov Model in addition to rigid base assumption. For this purpose, an interface that allows SAP2000 and MATLAB to be used simultaneously has been developed in MATLAB. It is observed that soil-structure interaction has a significant effect on the column longitudinal reinforcement ratio of reinforced concrete structures.
\end{abstract}

\section{Keywords}

OAPI; Reinforced concrete structures; SAP2000; Soil-structure interaction; Vlasov model

Received: 20 March 2018; Accepted: 29 March 2018

ISSN: 2630-5763 (online) (C) 2018 Golden Light Publishing ${ }^{\circledR}$ All rights reserved.

\section{Introduction}

The behavior of a structure is affected by interactions between the superstructure, the foundation system and the subsoil. Soil-structure interaction analyses the relations of these systems with each other. Soil behavior is the most complicated subjects in these relations. The reliability of structural design depends on how the soil structure interaction is modelled accurately and realistically. The columns at the base are usually considered as fixed in the design neglecting the soil effect. Soil effects are only considered in the design of foundation. The soil-structure interaction can be incorporated using Winkler model which soil structure is represented by infinitely close springs. However, in the Winkler model, being the simplest of the foundation models, the interaction between the springs are ignored and therefore the shear deformation of the subsoil is neglected. But the main disadvantage of these models is the necessity of determining the soil parameters. Modified Vlasov model facilitates the calculation of soil parameters depending on properties soil and the structure and type and the distribution of loads. There are many studies available on plates or beams resting on elastic foundation in literature [1-7]. Beside this, studies have been also carried out to investigate the effect of the subsoil on building behavior [8-17].

In this study, behavior of reinforced concrete structures is investigated by considering soilstructure interaction. In this way, an interface

\footnotetext{
* Corresponding author

E-mail:kozgan@yahoo.com
} 
developed in MATLAB is used simultaneously with SAP2000 v.15 package program. A 12-storey building is analyzed and results are compared for three different cases of support conditions. The soil parameters, natural vibration periods, column axial forces, column bending moments and longitudinal reinforcement ratios of the columns for various subsoil assumptions are presented cooperatively in figures and tables.

\section{Modified Vlasov model}

In the Modified Vlasov Model, subsoil reaction of a structure on elastic foundation is given by

$q_{z}=k w-2 t \nabla^{2} w$

in which $\mathrm{w}$ is the vertical surface displacement of subsoil, $\mathrm{k}$ is subgrade reaction modulus and $2 \mathrm{t}$ is the soil shear parameter as defined below

$$
\begin{aligned}
& k=\int_{0}^{H_{s}} \frac{E_{s}\left(1-v_{s}\right)}{\left(1+v_{s}\right)\left(1-2 v_{s}\right)}\left(\frac{\partial \phi(z)}{\partial z}\right)^{2} d z \\
& 2 t=\int_{0}^{H_{s}} G_{s} \phi(z)^{2} d z
\end{aligned}
$$

where $E_{s}, \quad v_{s}$ and $G_{s}$ are elasticity modulus, Poisson's ratio and shear modulus of subsoil respectively. $\phi(z)$ is the mode shape function describing the variation of vertical displacement within the subsoil, and it can be expressed as

$$
\phi(z)=\frac{1}{\sinh \gamma} \sinh \gamma\left(1-\frac{z}{H_{s}}\right)
$$

where $H_{s}$ is subsoil depth to rigid base, and $\gamma$ is the third soil parameter and it can be evaluated as

$$
\left(\frac{\gamma}{H_{s}}\right)^{2}=\frac{\left(1-2 v_{s}\right)}{2\left(1-v_{s}\right)} \frac{\int_{-\infty}^{+\infty} \int_{-\infty}^{+\infty}(\nabla w)^{2} d x d y}{\int_{-\infty}^{+\infty} \int_{-\infty}^{+\infty} w^{2} d x d y}
$$

In Eqs. (1-4), it is seen that the modulus of subgrade reaction, $k$, and the soil shear parameter, $2 t$, mode shape function $\phi(z)$, the depth of the subsoil, $H_{s}$, the third parameter of the soil, $\gamma$, and vertical surface displacement of the subsoil are dependent variables. Therefore, the solution of this complex soil-structure interaction problem can be performed using an iterative technique [4]. The third soil parameter, $\gamma$, is set to be equal to 1 to start iterations. The iteration is repeated until the latest and previous values of $\gamma$ within a prescribed tolerance.

\section{Methodology}

Versions of SAP2000 after V12 have OAPI (Open Application Programming Interface) feature to enable two-way data exchange. By using the OAPI functions, a MATLAB interface has been coded for calculating soil parameters iteratively. The model file created in SAP2000 program is opened using MATLAB interface and starting value of soil parameters are assigned the model. After running of the SAP2000 model, new soil parameters are calculated using MATLAB code with the soil surface displacements obtained from SAP2000. This iterative process is repeated until the difference between soil surface parameters computed in two successive iterations converges to a predetermined value [5]. The flowchart for the analysis of reinforced concrete structures resting on elastic foundation using Vlasov model is given in Fig. 1. 


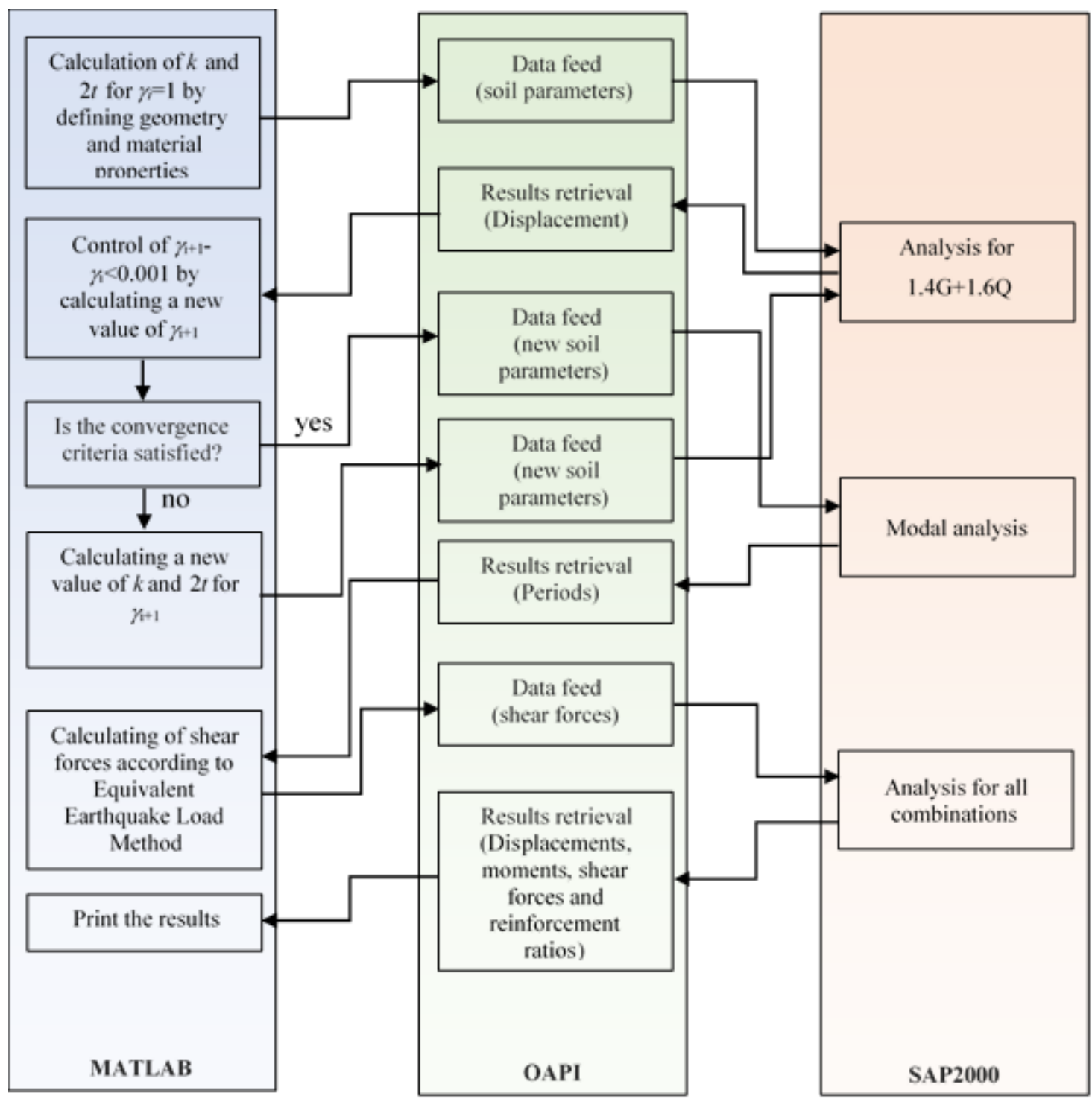

Fig. 1. Flowchart for the analysis of reinforced concrete structures on Vlasov model

\section{Numerical example}

\subsection{Data for structural system}

A 12-storey building with the formwork plan shown in Fig. 2 has been selected for the analyses. The story height is $3 \mathrm{~m}$. Young's modulus, Poisson's ratio and density of concrete are assumed as $28 \mathrm{GPa}, 0.2$ and $25 \mathrm{kN} / \mathrm{m}^{3}$ respectively. Crosssectional dimensions of structural elements are 50 $\times 50 \mathrm{~cm}^{2}$ for columns, $30 \times 60 \mathrm{~cm}^{2}$ for beams and 30 $\times 200 \mathrm{~cm}^{2}$ for shear walls. The superstructure is resting on a mat foundation with dimension of $18 \mathrm{~m}$ $\times 22 \mathrm{~m}$ and thickness of $75 \mathrm{~cm}$. Thickness of gas concrete walls on beams are $20 \mathrm{~cm}$ for outer walls and $10 \mathrm{~cm}$ for interior walls. Density of gas concrete wall has been taken as $5 \mathrm{kN} / \mathrm{m}^{3}$. Slabs with thickness of $15 \mathrm{~cm}$ are subjected to uniform load of $2 \mathrm{kN} / \mathrm{m}^{2}$.

The modulus of elasticity of subsoil is $94700 \mathrm{kN} / \mathrm{m}^{2}$ and Poisson's ratio for subsoil is 0.25 . Modulus of subgrade reaction is taken as 
$8650 \mathrm{kN} / \mathrm{m}^{3}$ for Winkler foundation subsoil model. The subsoil ends with a rigid rock layer after $8 \mathrm{~m}$.

Equivalent Earthquake Load Method is used for earthquake analysis according to Turkish Earthquake Regulation [18]. \pm 0.05 eccentricity and $1.4 \mathrm{G}+1.6 \mathrm{Q}, \mathrm{G}+\mathrm{Q} \pm \mathrm{E}_{\mathrm{x}}$ and $\mathrm{G}+\mathrm{Q} \pm \mathrm{E}_{\mathrm{y}}$ load combinations are considered for the analysis.

\subsection{Results}

Natural vibration periods and base shear forces for various foundation models are given in Table 1. As seen from the table, first natural vibration period increases when the soil effect is included in the behavior, and the highest value is obtained in the case of Vlasov model. The effects of soil-structure interaction cause natural vibration periods to increase. Base shear force calculated according to equivalent earthquake force method decreases in Vlasov model because the first natural vibration period increases.

Axial forces and bending moments of columns for various subsoil assumptions are presented in Fig. 3-4. Bending moments of columns are more affected compare to axial forces. Axial forces obtained by considering soil-structure interaction are greater for some columns and smaller for some columns than that of rigid base model. But it is certain that the subsoil effect is changing the axial forces significantly. As expected, the greater values of bending moments are obtained in Winkler and Vlasov model. Change in column bending moments causes longitudinal reinforcement ratios to increase.

Longitudinal reinforcement ratios of columns for various subsoil assumptions are presented in Fig. 5. Longitudinal reinforcement ratio of columns is calculated reducing two-dimensional combined bending to one dimensional combined bending in internal forces given by Figs. 3-4. Longitudinal reinforcement ratios of columns obtained by considering soil-structure interaction are greater than that of rigid base model. The column longitudinal reinforcement ratio in the rigid soil structure model is obtained at the minimum reinforcement ratio. In Winkler and Vlasov models, the column longitudinal reinforcement ratios are close to each other. Effects of subsoil on longitudinal reinforcement ratios of columns are clearly visible from the figure.

Table 1. Natural vibration period and base-shear force of structure

\begin{tabular}{lcccc}
\hline Soil-Structure Models & $\mathrm{T}_{1 \mathrm{x}}(\mathrm{sn})$ & $\mathrm{T}_{\mathrm{ly}}(\mathrm{sn})$ & $\mathrm{V}_{\mathrm{tx}}(\mathrm{kN})$ & $\mathrm{V}_{\mathrm{ty}}(\mathrm{kN})$ \\
\hline Rigid base & 0.8945 & 0.8902 & 6240.61 & 6240.61 \\
Winkler Model & 1.1813 & 1.0974 & 5019.95 & 5325,12 \\
Modified Vlasov Model & 1.2323 & 1.1912 & 4088.83 & 4776.86 \\
\hline
\end{tabular}

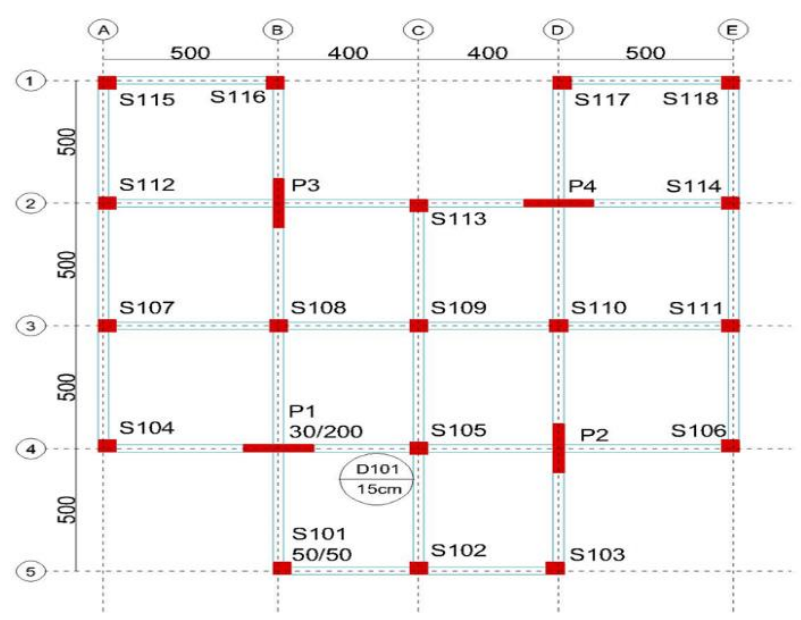

Fig. 2. Typical floor plan of the building 


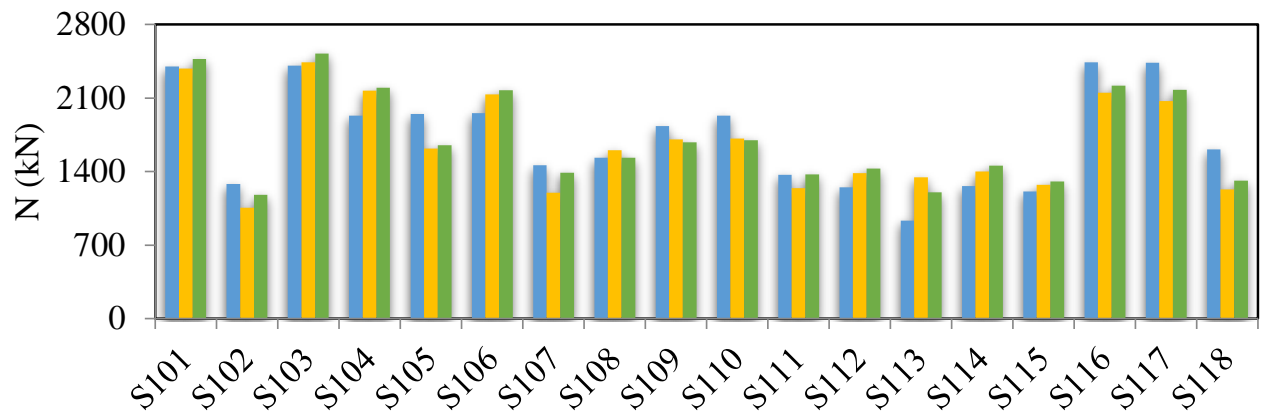

Numbers of the column

- Rigid soil-structure model $\quad$ Winkler Model $\quad$ Vlasov model

Fig. 3. The column axial loads

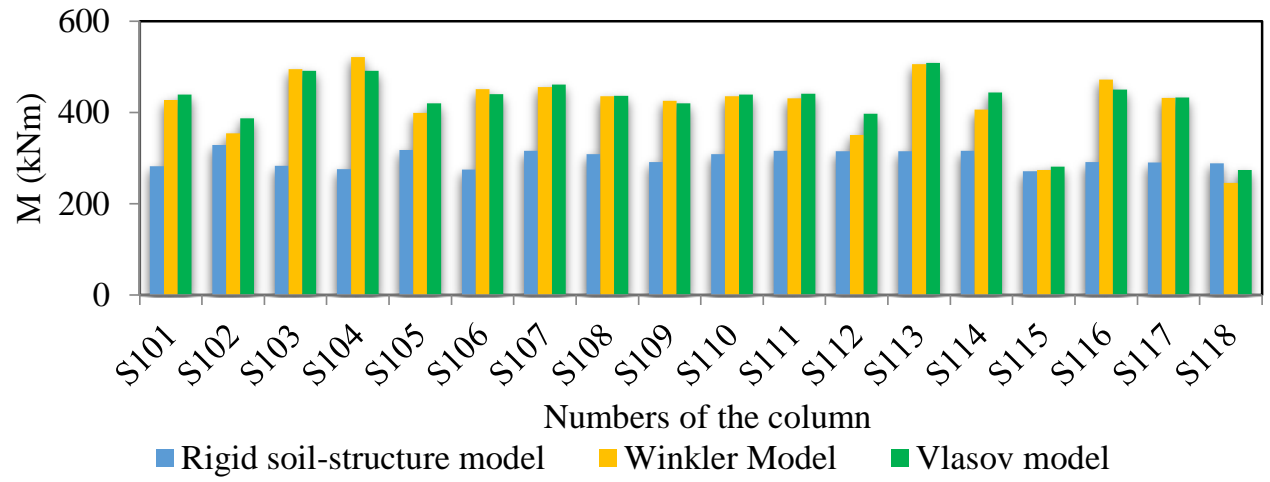

Fig. 4. The column bending moment

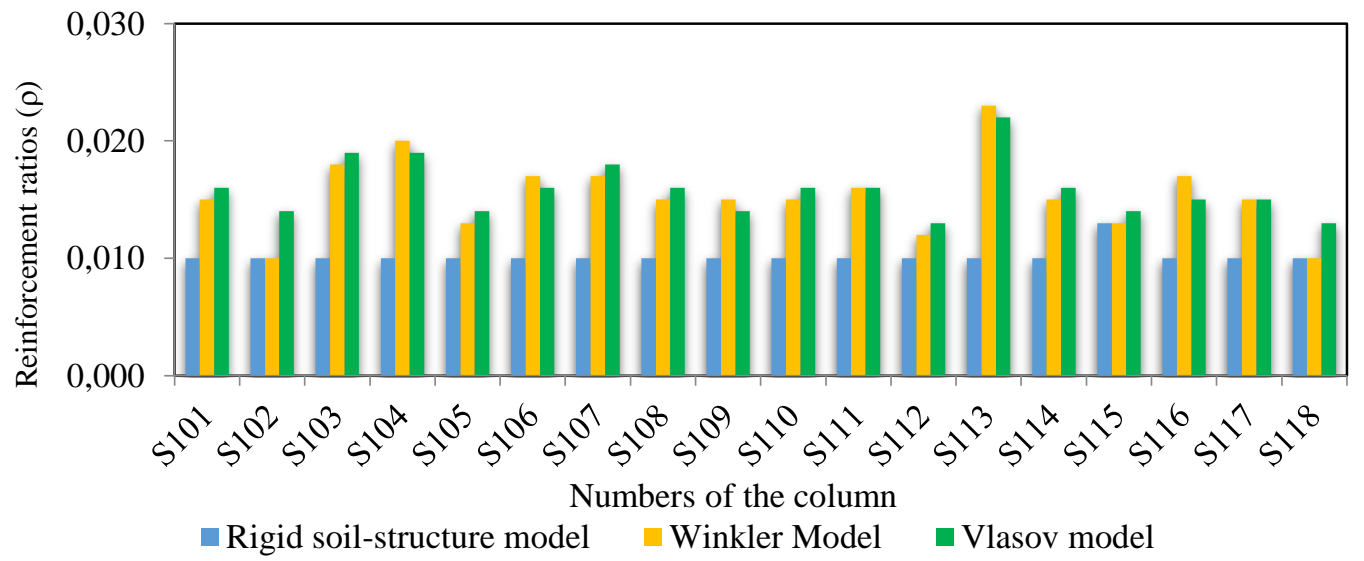

Fig. 5. Longitudinal reinforcement ratios of columns 


\section{Conclusion}

In this study, subsoil effects on the behavior of reinforced concrete structures are investigated. For this purpose, a 12-storey building is analyzed using rigid base assumption, Winkler and Vlasov subsoil models. A computing tool developed in MATLAB is presented in the study for the analysis of building-subsoil system. The results show that significant changes occur in internal forces and longitudinal reinforcement ratios of columns when subsoil effects are taken into consideration on analysis of building.

\section{References}

[1] Buczkowski R, Torbacki W (2001) Finite element modelling of thick plates on two-parameter elastic foundation. International Journal for Numerical and Analytical Methods in Geomechanics 25:1409-1427.

[2] Çelik M, Saygun, A (1999) A method for the analysis of plates on a two-parameter foundation, International Journal of Solids and Structures 36:2891-2915.

[3] Vallabhan CVG, Das YCP (1988) Parametric study of beams on elastic foundations, International Journal of Engineering Mechanics 114 (12):20722082.

[4] Vallabhan CVG, Das YC (1991) A refined model for beams on elastic foundations, International Journal of Solids and Structures, 27, (5):629-637.

[5] K1lı̧er S, Özgan K, Daloğlu AT. Analysis of mat foundation using Vlasov model, 2nd Soil Mechanics and Foundation Engineering Symposium: Soil-Structure Interaction in Theory and Practise, April 2014, Antalya, Turkey 151-156 (in Turkish).

[6] Sapuontzakis EJ, Katsikadelis JT (2002) A new model for slab and beam structures-comparison with other models. Computers and Structures 80:459-470.

[7] Wen PH, Aliabadi MH (2009) Boundary element formulations for Mindlin plate on an elastic foundation with dynamic load. Engineering Analysis with Boundary Elements 33:1161-1170.

[8] Karabörk T (2009) Nonlinear 3D Dynamic Analysis of Reinforced Concrete Structures by Means of Soil-Structure Interaction, Electronic Journal of Construction Technologies 5 (1):25-36 (in Turkish).
[9] Thangaraj DD, Ilamparuthi K (2012) Interaction analysis of mat foundation and space frame for non-linear behaviour of the soil. Bonfring International Journal of Industrial Engineering and Management Science 2 (4):33-40.

[10] Derdiman, MK (2013) Effects of Soils with Different Properties on Natural Period of Structure at RC High Rise Building, Afyon Kocatepe University Journal of Science and Engineering 13:9-15 (In Turkish).

[11] Frydrysek K, Janco R, Gondek H (2013) Solution of beams, frames and 3D structures on elastic foundation using FEM. International Journal of Mechanics 4 (7):362-369.

[12] Hamarat MA, Çalık Karaköse ÜH, Orakdöğen E. Seismic analysis of structures resting on two parameter elastic foundation, 15 WCEE, 2012, Lisboa

[13] Ionescu A, Calbureanu M, Negru M. Boussinesq method in seism analysis of a building structure using ANSYS program, WSEAS International Conference, Vouliagmeni, April 2013, Athens, Greece, 198-201.

[14] Ahmed M, Mohamed MH, Mallick J, Hasan MA (2014) 3D-analysis of soil-foundation-structure interaction in layered soil. Open Journal of Civil Engineering 4:373-385.

[15] Korkmaz KA, Demir F (2012) Soil structure interaction effects on structural earthquake behaviour, The Journal of Graduate School of Natural and Applied Sciences of Mehmet Akif Ersoy University 3(1):12-17 (In Turkish).

[16] Avcioğlu O, Orakdöğen E (2015) Time history analysis of structures on Vlasov type elastic subgrade, Pamukkale University Journal of Engineering Sciences 21(3):103-108 (In Turkish).

[17] Kahraman S, Misır İS, Özden G. The effects of using constant and variable subgrade modulus on the structural behaviour, Sixth National Conference on Earthquake Engineering, October 2007, İstanbul, Turkey, 217-228 (In Turkish).

[18] TDY-2007: Specifications for the building to be constructed in disaster areas, Ministry of Public Works and Settlement, Ankara, Turkey, 2007 (In Turkish). 